\title{
Choice and percentage reinforcement in pigeons
}

\author{
JAY MOORE \\ University of California, San Diego, La Jolla, California 92093
}

\begin{abstract}
Pigeons responded on a two-key concurrent chains choice procedure with the same level of percentage reinforcement on each key. During the initial links, a choice response on either key occasionally produced a conditioned reinforcer-which on one key was associated with a 15-sec, and on the other key with a 30-sec, interreinforcement interval-or an extinction stimulus. In Part 1, the initial links were equal. With successive decreases in the probability of a reinforcer, choice shifted from preference for the 15-sec terminal link toward indifference. In Part 2, the initial links were unequal and were arranged so that the shorter initial link preceded the 30-sec terminal link. At a high probability of a reinforcer, the pigeons again preferred the 15-sec terminal link. However, at a low probability, the pigeons reversed and preferred the alternate key. It was concluded that the conditioned reinforcers tended to become functionally equivalent at a low probability of a reinforcer, despite the nominally different interreinforcement intervals, with the result that choice was then modulated by the relative size of the initial links. The data are inconsistent with the view that choice and the strength of conditioned reinforcers are isomorphic with the reduction in delay to reward correlated with terminal link stimuli.
\end{abstract}

In a percentage reinforcement procedure, a reinforcing event, such as a food presentation, is randomly replaced by some other event, such as a blackout or a period of extinction. For example, in an experimental situation where responding in the presence of a white light occasionally produces food, percentage reinforcement may be implemented by replacing a certain percentage of the food presentations with blackout, where the order of food presentations and blackouts is random. Using this percentage reinforcement procedure, i.e., percentage reinforcement in connection with an unconditioned reinforcer, McMillan (1971), Neuringer and Chung (1967), Staddon and Innis (1969), and Zeiler (1972) have all reported that response rates were higher under percentage reinforcement than when only food presentations occurred.

Percentage reinforcement may also be used in connection with a conditioned reinforcer. For example, consider an experimental situation in which responding in the presence of a white light occasionally produces a green light, then responding in the presence of the green light produces food. In this situation, green is presumably a conditioned reinforcer for responding in white. Percentage reinforcement may be implemented in this situation by randomly replacing a certain percentage of green light

\footnotetext{
This experiment was used as partial fulfillment of the requirements for the PhD degree at the University of California, San Diego. The research and preparation of the manuscript were supported by NIH Grant 20752. The author wishes to express his thanks to Steve Buck, John Hale, Ron Menlove, and Ben Williams for their helpful comments. Reprints may be obtained from the author at the following address: Department of Psychology, C-009; University of California, San Diego; La Jolla, California 92093.
}

(conditioned reinforcing) periods with periods in which food is not available, signaled by a blue light.

Data have recently been reported from three experimental situations-a single key chain situation, an observing response situation, and a choice situation-that involve this latter percentage reinforcement procedure, i.e., percentage reinforcement in connection with a conditioned reinforcer. Taken together, these data suggest that the effect of percentage reinforcement in connection with a conditioned reinforcer parallels the effect in connection with an unconditioned reinforcer: the rate of responding maintained by a conditioned reinforcer may actually increase when periods of extinction are randomly substituted for the conditioned reinforcing stimulus. For example, in a single key chain situation, Kendall (1975) and Wilton and Clements (1971) exposed pigeons to a procedure in which there was not always a food reinforcer at the end of the terminal component (link) of a two-link chain. They found that when terminal link stimuli were differentially correlated with food, the pigeons pecked at a faster rate in the initial link of the chain when a reinforcer was obtained in half, rather than in all, of the terminal links. Similarly, in an observing response situation, Kendall (1973) exposed pigeons to a discrete trials procedure in which periods of key-light illumination ended with either food or no food. The outcome of a trial (i.e., either food or no food) was random, but the pigeon could produce a stimulus associated with the outcome by responding on an observing key. Kendall found that the pigeons pecked at a faster rate on the observing key when the probability of food on a given trial was 0.25 than when it was $0.50,0.75$, or 1.00 . In another observing response situation, McMillan (1974) exposed pigeons 
to a procedure in which either a variable-interval (VI) schedule of food reinforcment or extinction was in effect during the experimental session. The conditions of reinforcement alternated randomly within the session, but the pigeon could produce a stimulus associated with the then-prevailing condition of reinforcement by responding on an observing key. McMillan found that, in general, the pigeons pecked at a faster rate when the probability that the VI schedule was in effect was 0.20 than when it was 0.80 . Finally, in a choice situation, Kendall (1974a) arranged for a pigeon's choice responses on one key to be followed by a delay period that always ended with reinforcement. On the other key, choice responses were followed by an equally long delay period, but the delay ended with either reinforcement or timeout. When delay stimuli were uncorrelated with reinforcement and time-out, the pigeons pecked more often on the key leading to continuous (1.00) reinforcement. However, when the delay stimuli were correlated with reinforcement and time-out, then pigeons pecked more often on the key leading to intermittent $(0.50)$ reinforcement. This last result is especially intriguing, because, in one sense, it can be said that the pigeons preferred the choice alternative that provided reinforcement only half as often, a perplexity indeed (cf. Baum, 1973). In any case, stimuli signaling reinforcement availability in a percentage reinforcement situation, whether in a chain, observing response, or choice procedure, are powerful controlling variables.

The present experiment further investigated the effects of percentage reinforcement upon responding maintained by a conditioned reinforcer. The experiment used a modified concurrent chains choice procedure, similar to Kendall's (1974a). In the present procedure, a pigeon was presented with two concurrently available response keys, each illuminated by a stimulus associated with the initial link of a chain. Occasionally, a response on either key produced a stimulus change. The stimulus that appeared next on the key (i.e., the terminal link stimulus) was associated with either an interval schedule of primary reinforcement, in which case further responding produced food, or a period of extinction, in which case responding was ineffective (cf. Schneider, 1968). The probability of producing a food schedule, given a terminal link entry, was the same on each key. However, the terminal link stimuli associated with the interval schedules of food reinforcement, the conditioned reinforcers, differed in terms of the average interreinforcement interval (IRI): one conditioned reinforcer was associated with an average IRI of $15 \mathrm{sec}$, and the other with an average IRI of $30 \mathrm{sec}$. Thus, to compare the present experiment with Kendall (1974a), percentage reinforcement applied to both chains, not only one, and the terminal link food schedules were response- dependent interval schedules, rather than responseindependent delay schedules. Moreover, when the conditioned reinforcers did appear, they were associated with different rates of primary reinforcement.

Of major concern was the effect of parametrically decreasing the probability of a terminal link food schedule, given a terminal link entry on either key. If Kendall's (1974a) results, as well as the results of the chain and observing response studies, are indicative of a class of operations that modulates response rate and by inference the strength of conditioned reinforcers, then the effect of percentage reinforcement may override the effect of average IRI. That is, when a conditioned reinforcer alternates randomly with an extinction stimulus on each key, the conditioned reinforcers may become functionally equivalent, even though the conditioned reinforcer associated with the shorter IRI is stronger when percentage reinforcement is not involved. This result should then be evident in two different test situations. The first test situation involves the use of equal initial (choice) links. The pigeons will presumably prefer the chain with the shorter terminal link IRI at a high probability of producing a food schedule, but should tend toward indifference at a low probability. If the terminal link conditioned reinforcers become functionally equivalent through percentage reinforcement, then, given that the initial links are already equal, there may be little to differentiate functionally between the chains, and hence little to induce the pigeons to depart from responding equally on the chains. The second test situation involves the use of unequal initial links. The pigeons will presumably prefer chain VI $30 \mathrm{sec}$ VI $15 \mathrm{sec}$ to chain VI $15 \mathrm{sec}$ VI $30 \mathrm{sec}$ at a high probability of producing a food schedule, a systematic replication of Fantino's (1969) finding of preference for chain VI $90 \mathrm{sec}$ VI $30 \mathrm{sec}$ over chain VI $30 \mathrm{sec}$ VI $90 \mathrm{sec}$ However, the pigeons should reverse their preference, coming to respond more on the chain with the shorter initial link, at a low probability. A reversal of preference follows from the finding of Squires and Fantino (1971) that a chain VI $30 \mathrm{sec}$ VI $60 \mathrm{sec}$ is preferred to a chain VI $60 \mathrm{sec}$ VI $60 \mathrm{sec}$; that is, given terminal links of equal strength, preference is exhibited for the shorter of the unequal initial links. In the present experiment, if the two terminal links become functionally equivalent through percentage reinforcement, then the situation should reduce to something like that examined by Squires and Fantino (1971), and preference should again be exhibited for the chain with the shorter initial link.

\section{METHOD}

\section{Subjects}

Three adult male White Carneaux pigeons (B-22, B-20, 2958) with varied experimental histories served as the subjects. All 
pigeons were maintained at approximately $80 \%$ of their freefeeding weights.

\section{Apparatus}

A two-response-key version of the standard experimental chamber for pigeons (Ferster \& Skinner, 1957) was used. Conventional electromechanical programming apparatus, located in an adjacent room, controlled events occurring within the chamber and recorded the relevant data.

\section{Procedure}

The pigeons were exposed to concurrent chains with percentage reinforcement in each terminal link. In the usual concurrent chains procedure, each entry into a terminal link yields access to a food schedule and an unconditioned reinforcer. In the present procedure, whenever the pigeon produced either terminal link, an independently programmed probability device (either a stepper or a probability gate) determined whether a food schedule or a period of extinction would be in effect on that entry. The determination of whether or not the food schedule would be in effect was made immediately upon the onset of the terminal link, and the probability of a food schedule, given a terminal link entry, was the same, regardless of which terminal link was entered. If the food schedule was in effect, responding on the lighted key was reinforced according to the requirements of the terminal link schedule. If extinction was in effect, responding had no programmed consequence, and when a period of time equivalent to an IRI had elapsed, the initial links were reinstated immediately; there was no time-out between the end of a terminal link and the reappearance of the initial links. One terminal link provided food with an average IRI of $15 \mathrm{sec}$, and the other with an average IRI of $30 \mathrm{sec}$.

Both keys were white in the initial links. In the terminal links, the focal comparisons of the experiment were those in which one terminal link stimulus on each key was associated with a food schedule and one with extinction. In these comparisons, when the food schedule was in effect on the left key, the key was green, and when extinction was in effect, the key was blue. When a food schedule was in effect on the right key, the key was red, and when extinction was in effect, the key was amber. Technically, these terminal links are multiple (mult) schedules (a mult schedule is a compound schedule in which two or more component schedules alternate, each in the presence of a distinctive stimulus), and these comparisons will be referred to as the mult comparisons. The left panel of Figure 1 shows the sequence of events during the mult comparisons. In these comparisons, the conditioned reinforcing strengths of red and green were being tested.

As a control condition, the terminal links were occasionally mixed (mix) schedules (a mix schedule is a compound schedule in which two or more component schedules alternate, but in the presence of a common stimulus). When the terminal links were mix schedules, the pigeons encountered only green in the left terminal link or only red in the right terminal link, irrespective of whether there was going to be a reinforcer for that particular entry. The right panel of Figure 1 shows the sequence of events during the mix comparisons. For any one comparison, the terminal links were either both mult schedules or both mix schedules. That is, a mult schedule in one terminal link was never pitted against a mix schedule in the other.

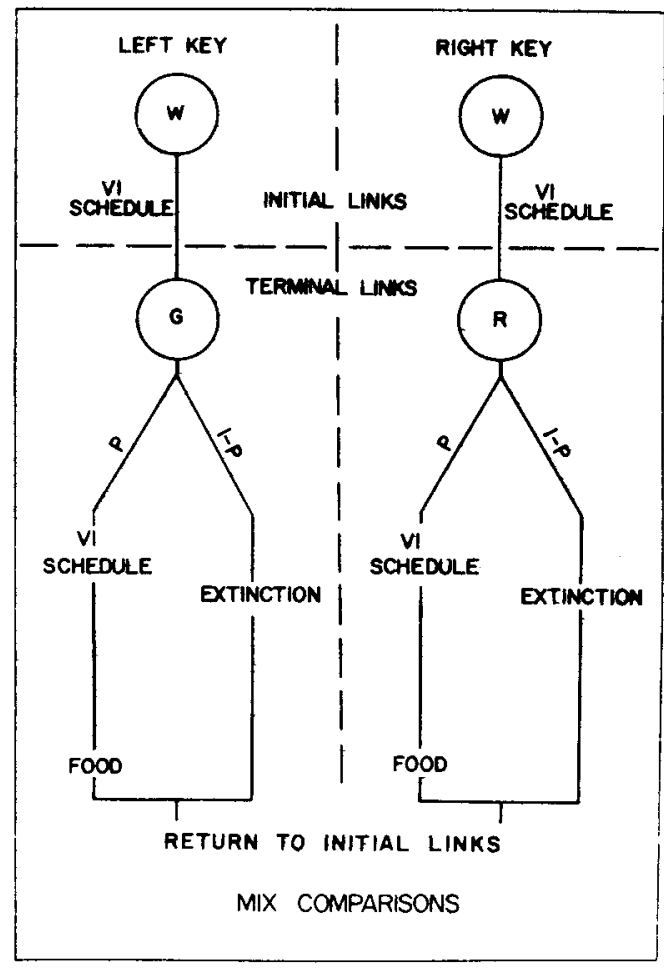

Figure 1. The sequence of events and key colors are shown for the mult comparisons (left panel) and the mix comparisons (right panel). During the terminal links, either a food schedule or a period of extinction was in effect. A probability gate, which operated during the transition between each initial link and each terminal link, selected randomly between the reinforcement conditions. In the mult comparisons, when a food schedule was in effect on the left key, the key was green; when extinction was in effect, the key was blue. When a food schedule was in effect on the right key, the key was red; when extinction was in effect, the key was amber. In the mix comparisons, regardless of whether a food schedule or extinction was in effect, the left key was green or the right key was red. Following completion of a terminal link, the white initial links were reinstated and the cycle began anew. The probability of producing a food schedule (P), given a terminal link entry, was the same for each chain. 
Table 1

Conditions and Data for Each Pigeon in Part 1

\begin{tabular}{|c|c|c|c|c|c|c|}
\hline \multirow[b]{2}{*}{ Condition } & \multirow{2}{*}{$\begin{array}{c}\text { Chain } \\
\text { Schedules }\end{array}$} & \multirow[b]{2}{*}{ Probability } & \multirow[b]{2}{*}{ Sessions } & \multirow{2}{*}{$\begin{array}{l}\text { Choice } \\
\text { Proportion } \\
\text { for } 30-s e c \\
\text { Terminal } \\
\text { Link } \\
\end{array}$} & \multicolumn{2}{|c|}{ Response/Minute } \\
\hline & & & & & Initial & Terminal \\
\hline \multicolumn{7}{|c|}{ Pigeon B-22 } \\
\hline 1 & $\begin{array}{l}\text { L VI } 30 \text { VI } 30 \\
\text { R VI } 30 \text { VI } 15\end{array}$ & 1.00 & 15 & .22 & $\begin{array}{l}10 \\
36\end{array}$ & $\begin{array}{l}56 \\
82\end{array}$ \\
\hline 2 & $\begin{array}{l}\text { L VI } 30 \text { VI } 30 \\
\text { R VI } 30 \text { VI } 15\end{array}$ & $0.50 \mathrm{mix}$ & 15 & .11 & $\begin{array}{r}6 \\
53\end{array}$ & $\begin{array}{l}44 \\
92\end{array}$ \\
\hline 3 & $\begin{array}{l}\text { L VI } 30 \text { VI } 30 \\
\text { R VI } 30 \text { VI } 15\end{array}$ & 0.50 mult & 15 & .35 & $\begin{array}{l}22 \\
40\end{array}$ & $\begin{array}{l}72 / 0 \\
92 / 0\end{array}$ \\
\hline 4 & $\begin{array}{l}\text { L VI } 30 \text { VI } 30 \\
\text { R VI } 30 \text { VI } 15\end{array}$ & $0.15 \mathrm{mix}$ & 15 & .22 & $\begin{array}{l}11 \\
40\end{array}$ & $\begin{array}{l}53 \\
69\end{array}$ \\
\hline 5 & $\begin{array}{l}\text { L VI } 30 \text { VI } 30 \\
\text { R VI } 30 \text { VI } 15\end{array}$ & 0.15 mult & 40 & .45 & $\begin{array}{l}25 \\
31\end{array}$ & $\begin{array}{r}81 / 0 \\
118 / 0\end{array}$ \\
\hline 6 & $\begin{array}{l}\text { L VI } 30 \text { VI } 15 \\
\text { R VI } 30 \text { VI } 30\end{array}$ & $0.15 \mathrm{mix}$ & 15 & .53 & $\begin{array}{l}17 \\
19\end{array}$ & $\begin{array}{l}62 \\
40\end{array}$ \\
\hline 7 & $\begin{array}{l}\text { L VI } 30 \text { VI } 15 \\
\text { R VI } 30 \text { VI } 30\end{array}$ & 0.15 mult & 15 & .21 & $\begin{array}{l}39 \\
10\end{array}$ & $\begin{array}{l}121 / 1 \\
104 / 0\end{array}$ \\
\hline 8 & $\begin{array}{l}\text { L VI } 30 \text { VI } 30 \\
\text { R VI } 30 \text { VI } 15\end{array}$ & 0.15 mult & 20 & .56 & $\begin{array}{l}30 \\
24\end{array}$ & $\begin{array}{r}85 / 1 \\
110 / 1\end{array}$ \\
\hline 9 & $\begin{array}{l}\text { L VI } 30 \text { VI } 15 \\
\text { R VI } 30 \text { VI } 30\end{array}$ & 0.15 mult & 15 & .38 & $\begin{array}{l}34 \\
21\end{array}$ & $\begin{array}{l}108 / 1 \\
108 / 0\end{array}$ \\
\hline 10 & $\begin{array}{l}\text { L VI } 30 \text { VI } 30 \\
\text { R VI } 30 \text { VI } 15\end{array}$ & 0.15 mult & 15 & .79 & $\begin{array}{l}45 \\
12\end{array}$ & $\begin{array}{r}87 / 0 \\
125 / 0\end{array}$ \\
\hline 11 & $\begin{array}{l}\text { L VI } 30 \text { VI } 30 \\
\text { R VI } 30 \text { VI } 15\end{array}$ & 1.00 & 15 & .33 & $\begin{array}{l}16 \\
33\end{array}$ & $\begin{array}{l}59 \\
76\end{array}$ \\
\hline \multicolumn{7}{|c|}{ Pigeon B-20 } \\
\hline 1 & $\begin{array}{l}\text { L VI } 30 \text { VI } 30 \\
\text { R VI } 30 \text { VI } 15\end{array}$ & 1.00 & 20 & .30 & $\begin{array}{l}27 \\
63\end{array}$ & $\begin{array}{l}119 \\
171\end{array}$ \\
\hline 2 & $\begin{array}{l}\text { L VI } 30 \text { VI } 30 \\
\text { R VI } 30 \text { VI } 15\end{array}$ & $0.50 \mathrm{mix}$ & 15 & .22 & $\begin{array}{l}15 \\
52\end{array}$ & $\begin{array}{l}130 \\
159\end{array}$ \\
\hline 3 & $\begin{array}{l}\text { L VI } 30 \text { VI } 30 \\
\text { R VI } 30 \text { VI } 15\end{array}$ & 0.50 mult & 15 & .38 & $\begin{array}{l}41 \\
68\end{array}$ & $\begin{array}{l}196 / 0 \\
151 / 0\end{array}$ \\
\hline 4 & $\begin{array}{l}\text { L VI } 30 \text { VI } 30 \\
\text { R VI } 30 \text { VI } 15\end{array}$ & $0.15 \mathrm{mix}$ & 15 & .17 & $\begin{array}{r}8 \\
39\end{array}$ & $\begin{array}{r}62 \\
136\end{array}$ \\
\hline 5 & $\begin{array}{l}\text { L VI } 30 \text { VI } 30 \\
\text { R VI } 30 \text { VI } 15\end{array}$ & 0.15 mult & 25 & .29 & $\begin{array}{l}26 \\
63\end{array}$ & $\begin{array}{l}198 / 0 \\
159 / 0\end{array}$ \\
\hline 6 & $\begin{array}{l}\text { L VI } 30 \text { VI } 15 \\
\text { R VI } 30 \text { VI } 30\end{array}$ & 0.15 mult & 45 & .48 & $\begin{array}{l}34 \\
31\end{array}$ & $\begin{array}{l}197 / 1 \\
128 / 0\end{array}$ \\
\hline 7 & $\begin{array}{l}\text { L VI } 30 \text { VI } 15 \\
\text { R VI } 30 \text { VI } 30\end{array}$ & $0.15 \mathrm{mix}$ & 20 & .35 & $\begin{array}{l}39 \\
21\end{array}$ & $\begin{array}{r}140 \\
70\end{array}$ \\
\hline 8 & $\begin{array}{l}\text { L VI } 30 \text { VI } 15 \\
\text { R VI } 30 \text { VI } 30\end{array}$ & 0.15 mult & 15 & .40 & $\begin{array}{l}46 \\
31\end{array}$ & $\begin{array}{l}170 / 1 \\
106 / 1\end{array}$ \\
\hline 9 & $\begin{array}{l}\text { L VI } 30 \text { VI } 30 \\
\text { R VI } 30 \text { VI } 15\end{array}$ & 0.15 mult & 15 & .61 & $\begin{array}{l}45 \\
29\end{array}$ & $\begin{array}{l}122 / 1 \\
109 / 1\end{array}$ \\
\hline 10 & $\begin{array}{l}\text { L VI } 30 \text { VI } 30 \\
\text { R VI } 30 \text { VI } 15\end{array}$ & 1.00 & 20 & .40 & $\begin{array}{l}32 \\
48\end{array}$ & $\begin{array}{l}46 \\
86\end{array}$ \\
\hline \multicolumn{7}{|c|}{ Pigeon 2958} \\
\hline 1 & $\begin{array}{l}\text { L VI } 30 \text { FI } 30 \\
\text { R VI } 30 \text { FI } 15\end{array}$ & 1.00 & 15 & .09 & $\begin{array}{r}11 \\
110\end{array}$ & $\begin{array}{l}23 \\
47\end{array}$ \\
\hline 2 & $\begin{array}{l}\text { L VI } 30 \text { FI } 30 \\
\text { R VI } 30 \text { FI } 15\end{array}$ & $0.50 \mathrm{mix}$ & 15 & .05 & $\begin{array}{r}5 \\
100\end{array}$ & $\begin{array}{r}32 \\
107\end{array}$ \\
\hline 3 & $\begin{array}{l}\text { L VI } 30 \text { FI } 30 \\
\text { R VI } 30 \text { FI } 15\end{array}$ & 0.50 mult & 15 & .14 & $\begin{array}{l}13 \\
78\end{array}$ & $\begin{array}{l}29 / 2 \\
36 / 3\end{array}$ \\
\hline
\end{tabular}


Table 1 continued-

\begin{tabular}{|c|c|c|c|c|c|c|}
\hline \multirow[b]{2}{*}{ Condition } & \multirow{2}{*}{$\begin{array}{c}\text { Chain } \\
\text { Schedules }\end{array}$} & \multirow[b]{2}{*}{ Probability } & \multirow[b]{2}{*}{ Sessions } & \multirow{2}{*}{$\begin{array}{l}\text { Choice } \\
\text { Proportion } \\
\text { for } 30-\mathrm{sec} \\
\text { Terminal } \\
\text { Link }\end{array}$} & \multicolumn{2}{|c|}{ Response/Minute } \\
\hline & & & & & Initial & Terminal \\
\hline 4 & $\begin{array}{l}\text { L VI } 30 \text { FI } 30 \\
\text { R VI } 30 \text { FI } 15\end{array}$ & $0.15 \mathrm{mix}$ & 15 & .09 & $\begin{array}{r}6 \\
61\end{array}$ & $\begin{array}{l}46 \\
37\end{array}$ \\
\hline 5 & $\begin{array}{l}\text { L VI } 30 \text { FI } 30 \\
\text { R VI } 30 \text { FI } 15\end{array}$ & 0.15 mult & 15 & .26 & $\begin{array}{l}24 \\
67\end{array}$ & $\begin{array}{r}71 / 4 \\
101 / 3\end{array}$ \\
\hline 6 & $\begin{array}{l}\text { L VI } 30 \text { FI } 15 \\
\text { R VI } 30 \text { FI } 30\end{array}$ & 0.15 mult & 20 & .49 & $\begin{array}{l}48 \\
47\end{array}$ & $\begin{array}{l}90 / 4 \\
88 / 2\end{array}$ \\
\hline 7 & $\begin{array}{l}\text { L VI } 30 \text { FI } 15 \\
\text { R VI } 30 \text { FI } 30\end{array}$ & $0.15 \mathrm{mix}$ & 15 & .35 & $\begin{array}{l}58 \\
30\end{array}$ & $\begin{array}{l}88 \\
48\end{array}$ \\
\hline 8 & $\begin{array}{l}\text { L VI } 30 \text { FI } 15 \\
\text { R VI } 30 \text { FI } 30\end{array}$ & 0.15 mult & 15 & .32 & $\begin{array}{l}46 \\
22\end{array}$ & $\begin{array}{l}70 / 6 \\
90 / 4\end{array}$ \\
\hline 9 & $\begin{array}{l}\text { L VI } 30 \text { FI } 30 \\
\text { R VI } 30 \text { FI } 15\end{array}$ & 0.15 mult & 15 & .49 & $\begin{array}{l}44 \\
46\end{array}$ & $\begin{array}{l}61 / 3 \\
66 / 4\end{array}$ \\
\hline 10 & $\begin{array}{l}\text { L VI } 30 \text { FI } 30 \\
\text { R VI } 30 \text { FI } 15\end{array}$ & 1.00 & & .08 & $\begin{array}{r}9 \\
98\end{array}$ & $\begin{array}{l}28 \\
30\end{array}$ \\
\hline
\end{tabular}

Note-Included are the chain schedules on the left ( $L$ ) and right (R) keys (All VI and FI values are in seconds), the scheduled probability of reinforcement per terminal link entry, whether the terminal links were mix or mult schedules, the number of sessions in each condition, and the choice proportion for the chain with the 30-sec terminal link. Also listed for each key are the responses per minute in both initial and terminal links. For the mult comparisons, response rates during the two components are separated and the rate during $S+$ is listed first. The choice proportions and response rate data are averages from the last five sessions in each condition.

Responding was examined under several probabilities of producing a food schedule. Reversals were performed in order to provide a better assessment of the preference. Of primary concern was the relative response rate or choice proportion: the rate at which the pigeon responded on one key divided by the rate at which it responded on both keys during the initial links. Unconditioned reinforcement consisted of 3-sec access to mixed grain. Individual sessions were terminated after $1 \mathrm{~h}$ or 40 reinforcements, whichever came first.

In part 1 , the concurrent initial links were equal: VI 30-sec schedules were in effect on each key. For pigeons B-22 and B-20, the terminal link schedules were VI $30 \mathrm{sec}$ and VI $15 \mathrm{sec}$. Thus, a chain VI 30-sec VI 15-sec schedule was in effect on one key, and a chain VI 30-sec VI 30-sec schedule was in effect on the other key. For pigeon 2958, the terminal link schedules were FI $30 \mathrm{sec}$ and FI 15 sec. Thus, a chain VI 30-sec FI 15-sec schedule was in effect on one key, and a chain VI 30-sec FI 30-sec schedule was in effect on the other. Table 1 presents the details of the schedules to which the pigeons were exposed in Part 1.

In Part 2, the concurrent initial links were unequal: a VI 15-sec schedule was in effect on one key, and a VI 30-sec schedule was in effect on the other key. The terminal link IRIs were the same as in Part 1, $15 \mathrm{sec}$ and $30 \mathrm{sec}$. Thus, pigeons B-22 and B-20 chose between chain VI $15 \mathrm{sec}$ VI $30 \mathrm{sec}$ and chain VI $30 \mathrm{sec}$ VI $15 \mathrm{sec}$, and pigeon 2958 chose between chain VI $15 \mathrm{sec}$ FI $30 \mathrm{sec}$ and chain VI $30 \mathrm{sec}$ FI $15 \mathrm{sec}$. Table 2 presents the details of the schedules to which the pigeons were exposed in Part 2.

\section{RESULTS}

The left panel of Figure 2 plots the choice proportion for chain VI $30 \mathrm{sec}$ VI (or FI) $30 \mathrm{sec}$ as a function of the probability of a food schedule (reinforcement) for Part 1. The right panel plots the choice proportion for chain VI $15 \mathrm{sec}$ VI (or FI) $30 \mathrm{sec}$ as a function of the probability of a food schedule for Part 2. The data are reported separately for mult comparisons (distinctive stimuli associated with food schedule and extinction) and mix comparisons (common stimulus associated with food schedule and extinction). Tables 1 and 2 present additional data for pigeons in Parts 1 and 2.

The left panel of Figure 2 indicates that all pigeons produced choice proportions well below 0.50 at the 1.00 probability level. This result is consistent with many other choice data, such as Herrnstein (1964). For the mult comparisons, as the probability of a food schedule decreased in accordance with percentage reinforcement, the choice proportion for the 30-sec terminal link increased monotonically to a level that was near 0.50 . For the mix comparisons, the choice proportion for the 30-sec terminal link also increased. However, at all probability levels, the mix choice proportions may be seen to be clearly less than the corresponding mult choice proportions.

Although Table 1 suggests instances of preference for the 15-sec terminal link in certain of the mult comparisons (pigeon B-22, Condition 7; pigeon 2958, Condition 5), there does not seem to be any evidence of comparable preference following a reversal of the schedules. The absolute response rates during the initial links of the mult comparisons show how the shift in choice proportions took place for individual pigeons. For pigeon B-22, the rate on the key with the 30-sec terminal link increased while the rate on the key with the 15 -sec terminal link remained relatively constant. For pigeon B-20, the rate on the key with the 30 -sec terminal 
Table 2

Conditions and Data for Each Pigeon in Part 2

\begin{tabular}{|c|c|c|c|c|c|c|}
\hline \multirow[b]{2}{*}{ Condition } & \multirow{2}{*}{$\begin{array}{c}\text { Chain } \\
\text { Schedules }\end{array}$} & \multirow[b]{2}{*}{ Probability } & \multirow[b]{2}{*}{ Sessions } & \multirow{2}{*}{$\begin{array}{c}\text { Choice } \\
\text { Proportion } \\
\text { for 30-sec } \\
\text { Terminal } \\
\text { Link } \\
\end{array}$} & \multicolumn{2}{|c|}{ Response/Minute } \\
\hline & & & & & Initial & Terminal \\
\hline \multicolumn{7}{|c|}{ Pigeon B-22 } \\
\hline 1 & $\begin{array}{l}\text { L VI } 15 \text { VI } 30 \\
\text { R VI } 30 \text { VI } 15\end{array}$ & 1.00 & 15 & .25 & $\begin{array}{r}8 \\
24\end{array}$ & $\begin{array}{l}62 \\
93\end{array}$ \\
\hline 2 & $\begin{array}{l}\text { L VI } 30 \text { VI } 15 \\
\text { R VI } 15 \text { VI } 30\end{array}$ & 1.00 & 15 & .25 & $\begin{array}{r}21 \\
7\end{array}$ & $\begin{array}{r}102 \\
48\end{array}$ \\
\hline 3 & $\begin{array}{l}\text { L VI } 30 \text { VI } 15 \\
\text { R VI } 15 \text { VI } 30\end{array}$ & $0.50 \mathrm{mix}$ & 15 & .26 & $\begin{array}{r}20 \\
7\end{array}$ & $\begin{array}{r}114 \\
45\end{array}$ \\
\hline 4 & $\begin{array}{l}\text { L VI } 30 \text { VI } 15 \\
\text { R VI } 15 \text { VI } 30\end{array}$ & 0.50 mult & 15 & .47 & $\begin{array}{l}25 \\
22\end{array}$ & $\begin{array}{l}66 / 0 \\
84 / 1\end{array}$ \\
\hline 5 & $\begin{array}{l}\text { L VI } 30 \text { VI } 15 \\
\text { R VI } 15 \text { VI } 30\end{array}$ & 0.30 mult & 25 & .52 & $\begin{array}{l}29 \\
32\end{array}$ & $\begin{array}{l}96 / 0 \\
94 / 0\end{array}$ \\
\hline 6 & $\begin{array}{l}\text { L VI } 30 \text { VI } 15 \\
\text { R VI } 15 \text { VI } 30\end{array}$ & 0.15 mult & 15 & .55 & $\begin{array}{l}21 \\
26\end{array}$ & $\begin{array}{l}85 / 0 \\
73 / 0\end{array}$ \\
\hline 7 & $\begin{array}{l}\text { L VI } 30 \text { VI } 15 \\
\text { R VI } 15 \text { VI } 30\end{array}$ & 0.15 mix & 30 & .42 & $\begin{array}{l}23 \\
17\end{array}$ & $\begin{array}{l}64 \\
46\end{array}$ \\
\hline 8 & $\begin{array}{l}\text { L VI } 30 \text { VI } 15 \\
\text { R VI } 15 \text { VI } 30\end{array}$ & 0.15 mult & 15 & .67 & $\begin{array}{l}20 \\
40\end{array}$ & $\begin{array}{r}106 / 0 \\
93 / 0\end{array}$ \\
\hline 9 & $\begin{array}{l}\text { L VI } 30 \text { VI } 15 \\
\text { R VI } 15 \text { VI } 30\end{array}$ & 1.00 & 15 & .37 & $\begin{array}{l}23 \\
14\end{array}$ & $\begin{array}{l}56 \\
53\end{array}$ \\
\hline \multicolumn{7}{|c|}{ Pigeon B-20 } \\
\hline 1 & $\begin{array}{l}\text { L VI } 30 \text { VI } 15 \\
\text { R VI } 15 \text { VI } 30\end{array}$ & 1.00 & 15 & .20 & $\begin{array}{l}96 \\
24\end{array}$ & $\begin{array}{l}172 \\
118\end{array}$ \\
\hline 2 & $\begin{array}{l}\text { L VI } 15 \text { VI } 30 \\
\text { R VI } 30 \text { VI } 15\end{array}$ & 1.00 & 15 & .22 & $\begin{array}{l}20 \\
71\end{array}$ & $\begin{array}{l}149 \\
200\end{array}$ \\
\hline 3 & $\begin{array}{l}\text { L VI } 30 \text { VI } 15 \\
\text { R VI } 15 \text { VI } 30\end{array}$ & $0.50 \mathrm{mix}$ & 15 & .07 & $\begin{array}{r}4 \\
50\end{array}$ & $\begin{array}{l}151 \\
128\end{array}$ \\
\hline 4 & $\begin{array}{l}\text { L VI } 30 \text { VI } 15 \\
\text { R VI } 15 \text { VI } 30\end{array}$ & 0.50 mult & 15 & .25 & $\begin{array}{l}26 \\
79\end{array}$ & $\begin{array}{l}232 / 8 \\
184 / 14\end{array}$ \\
\hline 5 & $\begin{array}{l}\text { L VI } 30 \text { VI } 15 \\
\text { R VI } 15 \text { VI } 30\end{array}$ & 0.30 mult & 25 & .55 & $\begin{array}{l}36 \\
43\end{array}$ & $\begin{array}{l}201 / 1 \\
151 / 0\end{array}$ \\
\hline 6 & $\begin{array}{l}\text { L VI } 15 \text { VI } 30 \\
\text { R VI } 30 \text { VI } 15\end{array}$ & 0.15 mult & 15 & .55 & $\begin{array}{l}41 \\
33\end{array}$ & $\begin{array}{l}162 / 1 \\
199 / 0\end{array}$ \\
\hline 7 & $\begin{array}{l}\text { L VI } 15 \text { VI } 30 \\
\text { R VI } 30 \text { VI } 15\end{array}$ & $0.15 \mathrm{mix}$ & 15 & .46 & $\begin{array}{l}21 \\
25\end{array}$ & $\begin{array}{l}100 \\
189\end{array}$ \\
\hline 8 & $\begin{array}{l}\text { L VI } 15 \text { VI } 30 \\
\text { R VI } 30 \text { VI } 15\end{array}$ & 0.15 mult & 15 & .67 & $\begin{array}{l}58 \\
32\end{array}$ & $\begin{array}{l}185 / 0 \\
191 / 3\end{array}$ \\
\hline 9 & $\begin{array}{l}\text { L VI } 15 \text { VI } 30 \\
\text { R VI } 30 \text { VI } 15\end{array}$ & 1.00 & 15 & .28 & $\begin{array}{l}19 \\
49\end{array}$ & $\begin{array}{l}115 \\
188\end{array}$ \\
\hline \multicolumn{7}{|c|}{ Pigeon 2958} \\
\hline 1 & $\begin{array}{l}\text { L VI } 15 \text { FI } 30 \\
\text { R VI } 30 \text { FI } 15\end{array}$ & 0.15 mult & 20 & .66 & $\begin{array}{l}55 \\
31\end{array}$ & $\begin{array}{l}35 / 4 \\
49 / 2\end{array}$ \\
\hline 2 & $\begin{array}{l}\text { L VI } 30 \text { FI } 15 \\
\text { R VI } 15 \text { FI } 30\end{array}$ & 0.15 mult & 25 & .61 & $\begin{array}{l}29 \\
45\end{array}$ & $\begin{array}{l}42 / 8 \\
47 / 3\end{array}$ \\
\hline 3 & $\begin{array}{l}\text { L VI } 30 \text { FI } 15 \\
\text { R VI } 15 \text { FI } 30\end{array}$ & 1.00 & 15 & .22 & $\begin{array}{l}88 \\
25\end{array}$ & $\begin{array}{l}43 \\
34\end{array}$ \\
\hline
\end{tabular}

Note-Included are the chain schedules on the left (L) and right (R) keys (all VI and FI values are in seconds), the scheduled proba. bility of reinforcement per terminal link entry, whether the terminal links were mix or mult schedules, the number of sessions in each condition, and the choice proportion for the chain with the 30-sec terminal link. Also listed for each key are the responses per minute in both initial and terminal links. For the mult comparisons, response rates during the two components are separated and the rate during $S+$ is listed first. The choice proportions and response rate data are averages from the last five sessions in each condition. 


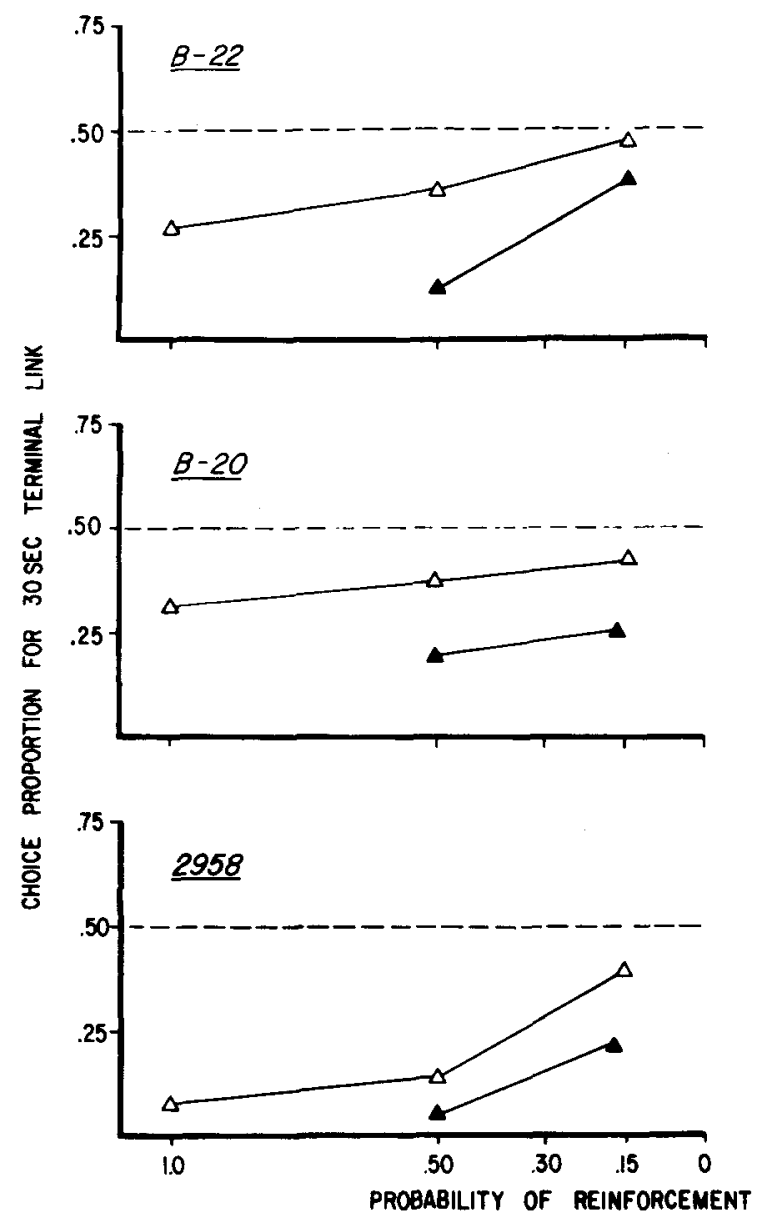

CHAIN VI 30 sec VI (or FI) 30 sec
CHAIN VI $30 \mathrm{sec}$ VI (or FI) 15 sec
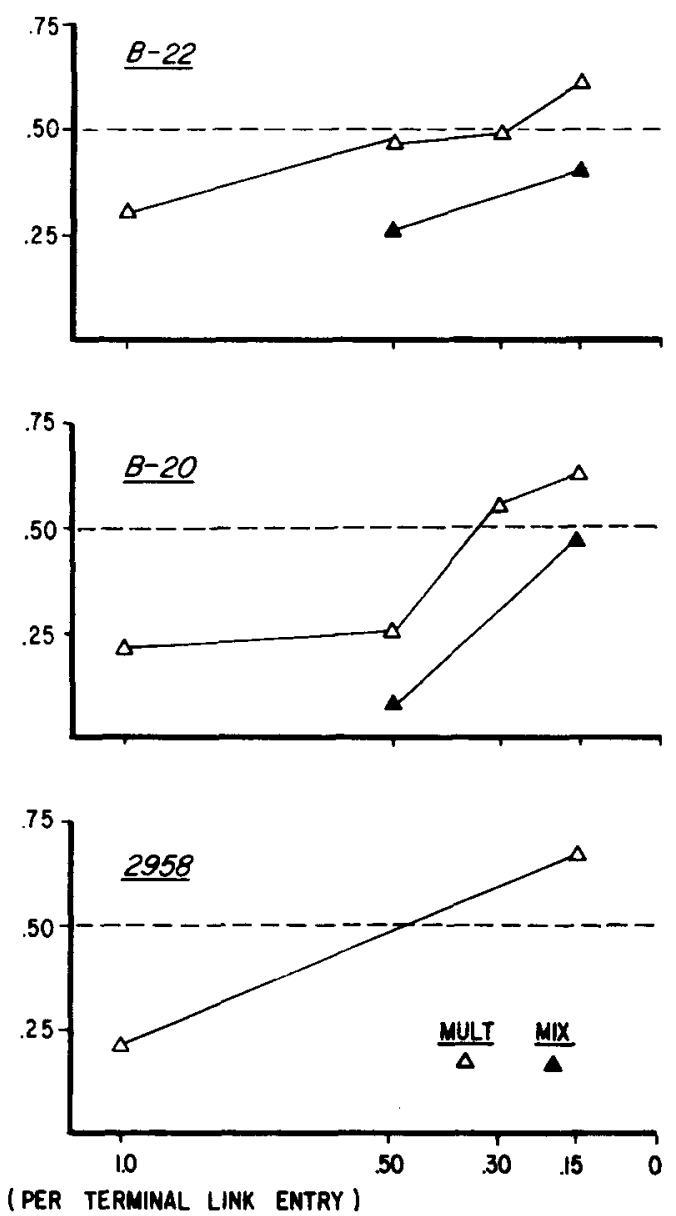

CHAIN VI $15 \mathrm{sec}$ VI (or FI) $30 \mathrm{sec}$
VS.
CHAIN VI $30 \mathrm{sec}$ VI (or FI) $15 \mathrm{sec}$

Figure 2. Choice proportions are plotted against probability of a food schedule (reinforcement) per terminal link entry for pigeons B-22, B-20, and 2958. The left panel presents the data from Part 1, where a chain VI 30 sec VI (or FI) 30 sec was pitted against a chain VI $30 \mathrm{sec}$ VI (or FI) 15 sec. The choice proportions in the left panel are stated in terms of the chain VI 30 sec VI (or FI) $30 \mathrm{sec}$ key, i.e., the chain with the 30-sec terminal link. The right panel presents the data from Part 2, where a chain VI 15 sec VI (or FI) $30 \mathrm{sec}$ was pitted against a chain VI $30 \mathrm{sec}$ VI (or FI) 15 sec. The choice proportions in the right panel are stated in terms of the chain VI $15 \mathrm{sec}$ VI (or FI) $30 \mathrm{sec}$ key, i.e., the chain with the 30-sec terminal link. The open symbols are the average choice proportions of the mult comparisons, and the closed symbols of the mix comparisons, taken from Tables 1 and 2.

link remained relatively constant, while the rate on the key with the 15 -sec terminal link decreased. For pigeon 2958, the rate on the key with the 30 -sec terminal link increased while the rate on the key with the 15-sec terminal link decreased. Thus, no single effect is consistent across all three pigeons. Unfortunately, more detailed analysis of the absolute response rates is hampered by variability in the data, apparently due to position bias (e.g., pigeon B-22, Conditions 9-10).

Table 1 also includes the absolute rates of responding during the terminal links. In general, terminal link response rates are higher in the mult comparisons than in the corresponding mix comparisons (e.g., pigeon B-20, Conditions 4-5). Also, response rates during $S+$ are somewhat higher at 0.15 -mult than at the 1.00 probability level. Thus, there seems to be some evidence of a contrast effect, produced by inserting periods of nonreinforcement (the extinction stimuli) into the chains (e.g., Reynolds, 1961; Taus \& Hearst, 1970; Wilton \& Gay, 1969).

The right panel of Figure 2 indicates that in Part 2, all pigeons again produced choice proportions well below 0.50 at the 1.00 probability level. This result is consistent with Squires and Fantino (1971). For the mult comparisons, as the probability of a food schedule decreased, the choice proportions for the 30-sec terminal link again increased monotonically, but this time to a level that was clearly above 0.50 for all pigeons. Thus, at the 1.00 probability level, 
all pigeons preferred chain VI $30 \mathrm{sec}$ VI (or FI) $15 \mathrm{sec}$, but at 0.15 -mult, all pigeons reversed and preferred chain VI $15 \mathrm{sec}$ VI (or FI) $30 \mathrm{sec}$. For the mix comparisons, the choice proportions for the $30-\mathrm{sec}$ terminal link increased to a level that was near 0.50; as in Part 1, the choice proportions for the mix comparisons were always less than those for the mult comparisons.

The absolute response rates during the initial links, listed in Table 2, reveal how the reversal of preference took place in Part 2. For pigeon B-22, the initial link rate on the key with the 30 -sec terminal link dramatically increased, while the rate on the other key remained relatively constant. For pigeons B-20 and 2958, initial link rate on the key with the 30 -sec terminal link increased while the rate on the other key decreased appreciably. Thus, the reversal of preference took place in all cases because of an increase in initial link rate on the key with the 30-sec terminal link. The total number of responses per minute on the two keys is slightly greater for pigeon B-22 at 0.15 -mult than at the 1.00 probability level, but slightly less for pigeons B-20 and 2958. Thus, the reversal in preference does not seem to be a peculiar kind of contrast effect that was somehow lccalized to the initial links, perhaps because the initial links always appeared immediately after a period of nonreinforcement in the terminal links. ${ }^{1}$ Also worthy of note is that there is much less variability in initial link response rates in Part 2 than in Part 1 , presumably because there was no trouble with key bias.

Table 2 also includes absolute response rates during the terminal links in Part 2. As in Part 1, terminal link response rates are generally higher in the mult comparisons than in the corresponding mix comparisons (e.g., pigeon B-22, Conditions 7-8). Also, terminal link response rates are somewhat higher during $\mathrm{S}+$ at 0.15 -mult than at the 1.00 probability level, consistent with the contrast effect noted in Part 1.

\section{DISCUSSION}

The present experiment employed a concurrent chains procedure to assess the effect of percentage reinforcement upon choice between terminal link conditioned reinforcers associated with 15- and 30-sec IRIs. In Part 1, the initial links were equal and the pigeons tended toward indifference with successive decreases in the probability of a reinforcer. In Part 2, the initial links were unequal and the pigeons reversed their preferences, coming to prefer the chain with the shorter initial link, with successive decreases in the probability of a reinforcer. Taken together, the results suggest that the relative effectiveness of the conditioned reinforcers tended to become approximately equal at a low probability of reinforcement, even though the effectiveness of the conditioned reinforcer associated with the 15 -sec IRI had been greater at a high probability. Accordingly, the pigeons' initial link choice responding at a low probability may then be interpreted as a function of the relative rate at which a terminal link conditioned reinforcer was produced. If the initial links are equal, then the relative rate is 0.50 , as in Part 1, and the pigeons tend toward indifference. However, if the initial links are unequal, then the relative rate on one key exceeds 0.50 , and the pigeons prefer that chain, as in Part 2.

These two findings - a tendency toward indifference in Part 1 but a complete reversal in preference in Part 2-are important in the analysis of choice and conditioned reinforcement for two interrelated reasons: (1) they suggest an additional class of variables that determines the amount of responding maintained by a conditioned reinforcer, and (2) they suggest a somewhat different version than conventionally accepted about responding in concurrent chains, from which theories relevant to conditioned reinforcement have been derived. The introduction to the present experiment reviewed recent data suggesting that the probability of a conditioned reinforcer is an important determiner of the level of responding that is maintained by a conditioned reinforcer. One study, in particular, deserves additional comment. Employing the concurrent chains procedure, Kendall (1974a) found that when terminal link stimuli were correlated with the availability of reinforcement, pigeons pecked at a faster rate on the key that led to a reinforcer on only half the terminal link entries than they did on the alternate key that led to a reinforcer on each entry. Thus, stimuli correlated with intermittent reinforcement controlled more antecedent behavior than stimuli correlated with continuous reinforcement. These provocative results are presumably inconsistent with theoretical assumptions that organisms "adopt a strategy" that "maximizes reinforcement" in a choice situation. Kendall's results suggest that at least within certain limits, partial reinforcement is stronger, in an absolute sense, than continuous reinforcement (note that the present experiment does not make this extreme claim; it found that, under percentage reinforcement, a stimulus correlated with a 30-sec IRI became approximately equal in strength to a stimulus correlated with a 15-sec IRI). As a general explanatory principle that accounts for the change in conditioned reinforcing value produced by percentage reinforcement operations, Kendall has suggested that the "more time spent in stimuli correlated with non-reinforcement, the more conditioned reinforcer value is enhanced"' (Kendall, 1975, p. 311; see also Notterman, 1951). This value hypoth- 
esis is highly relevant to the present study. That is, in the present study, the stimuli correlated with nonreinforcement are the terminal link stimuli associated with extinction for a given terminal link entry. When the probability of a reinforcer is very low, the pigeon is necessarily exposed more frequently to terminal link extinction stimuli, and consequently spends a greater proportion of session time in the presence of a key light that is associated with nonreinforcement. Thus, when any key light that is associated with food does appear, its value may be such that the nominal IRI associated with its presence may be relatively unimportant in a choice setting. Given that terminal link conditioned reinforcers do become functionally equivalent at a low probability, the size of the initial links would then exert control over choice, as described earlier.

Although at first blush the results of Kendall's (1974a) and the present study may appear counterintuitive, they may simply be another demonstration of the general phenomenon of partial reinforcement. Perhaps the use of correlated stimuli in percentage reinforcement is somehow analogous to partial reinforcement using primary reinforcers (e.g., Wilton, 1972). Indeed, it is useful to note here that without correlated stimuli, pigeons prefer continuous to percentage reinforcement (Kendall, 1974a; Schneider, 1968). Unfortunately, analysis of the absolute response rates during the initial links does not provide unequivocal support for this speculation. In the present experiment, for example, it might be expected that response rates should increase on both keys, with that on one key increasing faster than that on the other, thereby accounting for an increase in choice proportion. When there was an increase in choice proportion in the present study, there was never a decrease in absolute response rate on that key; for five out of six cases, there was an increase, and for the sixth case, the rate remained the same. However, the absolute response rate on the second key never showed a corresponding increase. This pattern on the second key might be attributable to some hitherto unspecified interaction in concurrent schedules involving conditioned reinforcement, since such an effect occurs with primary reinforcement (Catania, 1963).

It should perhaps be noted here that choice between mix and multiple schedules produces an effect that may be related to the present one. Eckerman (1973) arranged for pigeons' pecking in either of two conditions to produce either an FI 10-sec or an FI $60-\mathrm{sec}$ schedule of reinforcement. The stimuli produced by pecks during one condition were uncorrelated (mix) but during the other condition correlated (mult) with the schedule that was produced, and the likelihood of the FI 10-sec schedule was then varied systematically. As the likelihood of the FI 10-sec schedule grew less (up to about 0.13), the pigeons pecked relatively more in the condition that led to differential stimuli. Again, an inverse relation may be noted: the fewer times the more positive consequence is produced (the mult stimulus associated with FI $10 \mathrm{sec}$ ), the greater the relative rate and, by definition, the greater its relative effectiveness. In any case, no current single theory appears adequate to account for all these related data, from observing responses and choice procedures. Nevertheless, despite the lack of a theory, correlated stimuli in the context of percentage reinforcement are powerful determiners of behavior.

The present results also pertain to the structure of behavior in concurrent chains. One previously successful model of concurrent chains behavior is Fantino's delay reduction hypothesis (Fantino, 1977). This model suggests that pigeons' choice in concurrent chains may be described by comparing the relative reductions in average delay to reward correlated with the terminal link stimuli (see Fantino, 1977 , for the full development of the quantitative aspects of the model). Now, under percentage reinforcement, the average time to reward becomes very long in both Parts 1 and 2. Given terminal link conditioned reinforcers associated with 15 and $30-\mathrm{sec}$ IRIs, the ratio of reductions in delay yields a figure that should approach 0.50 with successively lower probabilities of reinforcement per entry. The model does describe the data from Part 1, but fails to account for the reversal in preference in Part 2. The model requires a choice proportion slightly below 0.50 at 0.15 -mult, yet the pigeons actually exhibit a preference that is above 0.60 (note that the model also does not account for Kendall, 1974a, for similar reasons). While it is unclear whether there are any correspondence rules in the hypothesis to accommodate this kind of percentage reinforcement, Fantino has recently argued the applicability of his hypothesis to such situations: "Only the delay reduction hypothesis of conditioned reinforcement is consistent with what is known about observing and choice" (Fantino, 1977); "The delay reduction hypothesis may be broadened readily to encompass improvement in reinforcer ... probability" (Fantino, 1977). It may also be noted that Kendall (1974b) has found that, under certain conditions, pigeons will peck in an observing response procedure to produce a stimulus that does not signal a reduction in delay to reward, another clear violation of the model. In any case, a delay reduction account appears to need further development.

It seems that choice and the strength of conditioned reinforcers are not isomorphic with the reduction in delay to reward correlated with a given conditioned reinforcer. An equally plausible account of responding in concurrent chains is that initial link size must be dissociated from those variables that determine the strength of conditioned reinforcers. 
That is, terminal link events determine the strength of terminal link conditioned reinforcers, and then each terminal link combines with its preceding initial link to control a given level of responding. In terms of relative contribution to responding, terminal link variables presumably are weighted more heavily than are initial link variables. Thus, preference for chain VI $30 \mathrm{sec}$ VI $15 \mathrm{sec}$ over chain VI $15 \mathrm{sec}$ VI $30 \mathrm{sec}$ (without percentage reinforcement) presumably reflects that the control exerted by a higher density of primary reinforcement in the terminal links outweighs the difference in the initial links. A delay reduction account is molar, in that it incorporates events on both chains into a single composite variable. For the time being, a molecular account, one which separates relevant variables, appears the more profitable.

In summary, the present experiment examined choice in a concurrent chains situation where terminal link stimuli were differentially associated with whether or not a reinforcer was presented for an entry into a terminal link. The probability that a conditioned reinforcer would occur modulated choice and by inference the strength of terminal link stimuli. In order to make even ordinal predictions about the direction of preference, it was necessary to dissociate the various features of the chains (e.g., initial from terminal link parameters) rather than combine them into a single composite variable, such as average IRI, and make predictions therefrom.

\section{REFERENCES}

Baum, W. The correlation based law of effect. Journal of the Experimental Analysis of Behavior, 1973, 20, 137-153.

Catania, A. C. Concurrent performances: Reinforcement interaction and response independence. Journal of the Experimental Analysis of Behavior, 1963, 6, 252-263.

ECKERMAN, D. E. Uncertainty reduction and conditioned reinforcement. Psychological Record, 1973, 23, 39-47.

Fantino, E. Choice and rate of reinforcement. Joumal of the Experimental Analysis of Behavior, 1969, 12, 723-730.

Fantino, E. Conditioned reinforcement. II: Choice and information. In W. Honig \& J. E. R. Staddon (Eds.), Handbook of operant behavior. New York: Prentice-Hall, 1977.

Ferster, C. B., \& Skinner, B. F. Schedules of reinforcement. New York: Appleton-Century-Crofts, 1957.

HeRRNSTEIN, R. J. Secondary reinforcement and rate of primary rein forcement. Journal of the Experimental Analysis of Behavior, 1964, 7, 27-36.

Kendall, S. B. Effects of two procedures for varying information transmission on observing responses. Journal of the Experimental Analysis of Behavior, 1973, 20, 73-83.

Kendall, S. B. Preference for intermittent reinforcement. Journal of the Experimental Analysis of Behavior, 1974, 21, 463-473. (a)

KENDALL, S. B. Maintenance of observing responses with the less highly valued stimulus in pigeons. Animal Learning \& Behavior, 1974, 2, 210-214. (b)
Kendall, S. B. Enhancement of conditioned reinforcement by uncertainty. Journal of the Experimental Analysis of Behavior, $1975,24,311-314$.

McMillan, J. C. Percentage reinforcement of fixed-ratio and variable interval performances. Journal of the Experimental Analysis of Behavior, 1971, 15, 297-302.

McMillan, J. C. Average uncertainty as a determinant of observ. ing behavior. Journal of the Experimental Analysis of Behavior, 1974, 22, 401-408.

Neuringer, A. J. \& \& Chung, S. -H. Quasi-reinforcement: Control of responding by a percentage reinforcement schedule. Journal of the Experimental Analysis of Behavior, 1967, 10, 45-54.

NotTERman, J. M. A study of some relations between periodic reinforcement, discrimination training, and secondary reinforcement. Journal of Experimental Psychology, 1951, 41, 161-169.

REYNOLDS, G. S. Behavioral contrast. Joumal of the Experimental Analysis of Behavior, 1961, 4, 57.71.

SCHNEIDER, J. W. Effects of percentage reinforcement on choice in a concurrent chain schedule. Psychonomic Science, 1968, 12, 211-212.

Staddon, J. E. R., \& InNIs, N. K. Reinforcement omission on fixed interval schedules. Joumal of the Experimental Analysis of Behavior, 1969, 12, 689-700.

SQUiRes, N, \& Fantino, E. A model for choice in simple concurrent and concurrent chain schedules. Journal of the Experimental Analysis of Behavior, 1971, 15, 27-38.

Taus, S., \& HEarst, E. Effects of intertrial (blackout) duration on response rate to a positive stimulus. Psychonomic Science, 1970 , $19,265-276$.

WILTON, R. N. The role of information in the emission of observing responses and partial reinforcement acquisition phenomena. Leaming and Motivation, 1972, 3, 479-499.

Wilton, R. N., \& Clements, R. O. Observing responses and informative stimuli. Journal of the Experimental Analysis of Behavior, 1971, 15, 199-204.

Wrlton, R. N., \& GAY, R. A. Behavioral contrast in chained schedules. Journal of the Experimental Analysis of Behavior, $1969,12,905-910$.

ZeILER, M. D. Fixed interval behavior: Effects of percentage reinforcement. Joumal of the Experimental Analysis of Behavior, $1972,17,177-189$.

\section{NOTE}

1. In an effort to investigate a possible contribution of a contrast effect, pigeons were exposed to the same chains as in Part 2, but with a 30-sec period of blackout (complete darkness) interposed between the conclusion of every terminal link and the reappearance of the initial links. It was thought that the blackout, which was an extinction stimulus common to both keys, might deter the development of contrast on one key, if indeed the higher rate in Part 2 was a simple contrast effect. The test in this condition, then, was whether preference would be maintained with the blackout, an outcome which argues against contrast, or whether responding would tend toward indifference, an outcome which would implicate contrast. The pigeons maintained their preferences, and on the basis of these and earlier data, further contrast interpretations were discounted. Moreover, as Kendall (1975) has recently pointed out, contrast in a chain schedule seems to occur in the terminal component rather than in the initial component (Wilton \& Gay, 1969).

(Received for publication April 16, 1976; revision accepted August 8, 1976.) 